\title{
Almond Germplasm in Bostanlyk Area (Uzbekistan): Preservation and Exploitation
}

F. Sottile ${ }^{1, \mathrm{a}}$, M.B. Del Signore ${ }^{1}$, M. Tsoy ${ }^{2}$, A. Abdurasulov ${ }^{3}$ and C. Peano ${ }^{4}$

${ }_{1}^{1}$ Dipartimento di Scienze Agrarie e Forestali, University of Palermo, Palermo, Italy

${ }^{2}$ Slow Food Convivium, Tashkent, Uzbekistan

${ }^{3}$ Schroeder Research Institute, Agriculture Department, Bostanlyk, Uzbekistan

${ }^{4}$ Dipartimento di Scienze Agrarie, Forestali e Alimentari, University of Torino, Grugliasco (TO), Italy

Keywords: almond, genetic resources, cultivars, germplasm preservation

\begin{abstract}
Almond germplasm has been studied throughout the world with high diversity identified in the Mediterranean Basin. Each production region is based on specific types of cultivars, frequently without a real commercial strategy. For this reason we still have a wide range of particularly interesting almond germplasm, especially for genetic improvement. In some parts of the world, local germplasm is still interesting for a restricted almond industry, usually related to a local or internal consumption. In this paper we provide details about the almond industry in the traditional area of Bostanlyk, Uzbekistan. Since 2007 a specific approach to evaluate the local germplasm has been applied; the most important aspects describing the growing areas and the local history. The pomological traits are reported in a project carried out by the Slow Food International Foundation for Biodiversity.
\end{abstract}

\section{INTRODUCTION}

Agriculture in Uzbekistan has an ancient tradition; this geographical area could be considered a possible center of origin of many tree species and nuts (i.e., almond, pistachio, walnut) and still has very ancient traditions related to the consumption and processing of local products. However, there are rare historical reports of an almond industry in this country, partly because of reduced availability of official documents, especially due to a long period of socio-cultural isolation. The almond tree, moreover, has rarely been considered as a cash crop although it was part of the cultural tradition where it has spread significantly. The almond plant, in fact, in its wild appearance, probably accompanied the evolution of man in this country, contributing in completing the power home-supply and to mitigate the effects of famine in times of war and isolation.

With this approach, for centuries the creation of specialized almond orchards is not evidenced; it grew, however, in the wild form, often propagated by seed and with limited commercial interest. Today, in Uzbekistan there are approximately 2500 ha of almond but only $40 \%$ is under cultivation for direct consumption and food processing (Mirmahsud et al., 2003).

In the territories of the Bostanlyk district, located in the north-western territories of Tien Shan, it is still possible to follow the Great Silk Road, the way of different peoples and travelers. On this route, travelers transported goods and, with their stops and trade also left and collected seeds, and disseminated plant species along the known world (Barbera et al., 2005).

The villages of Brichmulla and Khumsan were the most developed in the district of Bostanlyk. In the surrounding agricultural areas, a series of almond accessions developed which found in this environment a favorable climatic condition: the high mountains protect them from the cold north winds, while mild air coming from the West mitigate winter temperatures, thus creating a condition climatically suitable for many species, especially for blooming and to bear abundant fruit (Esenbaev, 1981).

Over the centuries, the natural almond orchards have been selected by farmers of

${ }^{\mathrm{a}}$ francesco.sottile@unipa.it 
the two villages who were responsible in the nutrition and food culture of the area. Only in more recent years such material and other more recent selections were also subjected to morphological and biometric analysis and approached by the Slow Food Foundation for Biodiversity through the project of Slow Food Presidia.

\section{MATERIALS AND METHODS}

The characterization of the genetic material selected over the years has been initially approached and carried out at the Schroeder Institute which is based in Khumsan and leads a large technical and agronomic activity within the almond orchards. In 2007, the International Slow Food Foundation for Biodiversity launched a project to restore and enhance the indigenous and traditional almond production. Together with the University of Palermo, it has begun the bio-morphological characterization of the indigenous almond germplasm. Following this activity, 12 genotypes have been definitively characterized and addressed to a propagation protocol for dissemination in new plantings.

For a more detailed characterization of the selected plant material, in 2012 a sample of fruits of 15 accessions, selected under a wide biodiversity, was taken and subsequently subjected to pomological analysis for the determination of the principal distinctive characters defined by a list of officially recognized descriptors (IPGRI, 1985). At the laboratories of the University of Palermo the weight in shell, diametrical ratios, the kernel rate, measures of the almond, the percentage of twins and the hardness of the shell were determined. All the observed data are reported in Table 1.

\section{RESULTS}

An initial part of the experimental work involved the characterization of the material, identified and characterized at the Schroeder Institute. The main features detected for each cultivar are reported in Table 1. It is interesting to evidence that all the accessions are rich in fats according to an almond-type more similar to the Mediterranean type $(>55 \%)$ rather than the American ones although they have been clearly selected for the high kernel rate and a reduced hardness of the shell.

The analysis of the results obtained by the description of the samples on the additional 15 accessions showed the presence of high genetic diversification; the shelling rate was on average higher $(>40 \%)$ in 5 accessions while only 2 had ratios $<20 \%$. Only 3 accessions have almonds in shell exceeding $3 \mathrm{~g}$ and 5 accessions showed a total absence of twins. For this aspect, a single accession, in contrast, showed over $60 \%$ double kernels.

\section{CONCLUSIONS}

The evaluation of local almond genetic resources, developed in the Bostanlyk, confirmed the existence of a large-scale biodiversity that still allows recovery of accessions of particular interest and potential use for a sector that is assuming increasing importance in the country.

The product, obtained in traditional small farms in Brichmulla and Khumsan, is often used locally for direct consumption or sold to merchants who mainly trade it in the capital Tashkent. A substantial part of the product is processed following traditional recipes handed down within villages.

The almond is an intrinsic part of the life of the villages. Their inhabitants use the almonds in cooked sweets, in baking goods and for medical purposes. Presently, the almonds are widely used fresh or dried; when mixed up with honey. It forms the local dish called "shirilik". Inhabitants of Brichmulla use old recipes for cooking and produce the almond sweet called "khashtak". Khashtak means seven ingredients, four of which reach us in their traditional form: kuraga (dried apricots), almond (or walnut), raisin and honey. Khashtak is produced by local people and sold in many markets in Tashkent and throughout Uzbekistan.

However, there are still conditions that cause a loss of biological diversity linked to this species mainly because of the necessary subsistence of the people who use wood as fuel for home-heating. Unfortunately, many villagers of Bostanlyk region cannot afford 
buying coal or gas. Therefore, people harvest wood for cooking and heating, and consequently reduce or, sometimes, destroy forestlands and almond orchards. This brings about the adverse impacts of reduction of habitat and a decrease in the variety of almonds available.

In order to preserve the almond areas and spread of the species into specialized orchards, the Schroeder Institute has initiated a process of propagation by grafting of the major accessions. The activity of multiplication was initiated in the experimental facilities of Khumsan and involves the production of one-year old grafted trees which can be freely distributed to growers who are interested in increasing the almond production.

\section{The Presidium}

The Slow Food Presidia project (www.slowfoodfoundation.com) is a very important communication tool that, through direct information and online facilities as well as through international events, enables growers and their product to be known even outside the country and to initiate an effective diffusion of the product. The Presidium "Bostanlyk Ancient Varieties of Almond" was created to protect and promote this extraordinary heritage of biodiversity of the Western Tien Shan. Currently, it involves ten producers from the Khumsan and Brichmulla villages closely cooperating with the Schroeder Research Institute of the Bostanlyk region in order to help find new source of income for local producers.

\section{Literature Cited}

Barbera, G., Monte, M. and Sottile, F. 2005. The almond Museo vivente "F. Monastra": from genetic resources rescue to germplasm collection. Opt. Medit. Serie A. N. 63:7984.

Esenbaev, Z.I., Safarov, R.A., Gaibov, N.G., Mirzaev, M.M. and Penson, M.M. 1981. Orchards of Uzbekistan (in Uzbek, Russian, and English). Uzbekistan. Tashkent.

IPGRI 2004. Country report on the state of plant genetic resources for food and agriculture - Uzbekistan.

IPGRI 1985. Descriptor List for Almond (revised).

Mirzaev, M.M. and Djavacynce, U.M. 2003. The Schroeder Institute in Uzbekistan: Breeding and germplasm collections. HortSci. 38(7). 


\section{$\underline{\text { Tables }}$}

Table 1. Phenological, carpological and some chemical characteristics of almond cultivars described at the Schroeder Institute (Uzbekistan).

\begin{tabular}{lccccccc}
\hline Cultivar & $\begin{array}{c}\text { Blooming } \\
\text { time* }\end{array}$ & $\begin{array}{c}\text { Fruit } \\
\text { ripening }\end{array}$ & $\begin{array}{c}\text { Shell } \\
\text { type** }\end{array}$ & $\begin{array}{c}\text { Nut } \\
\text { weight }\end{array}$ & $\begin{array}{c}\text { Kernel } \\
\text { rate }\end{array}$ & Fat & Yield \\
\cline { 2 - 8 } & & & & $\mathrm{g}$ & $\%$ & $\%$ & $\mathrm{~kg}$ \\
\hline Bonstanlyk & $\mathrm{E}$ & $2^{\text {nd }}$ Sept. & $\mathrm{H}$ & 2,1 & 44,1 & 59,6 & 10,5 \\
Zavetny & $\mathrm{ML}$ & $1^{\text {st }}$ Sept. & $\mathrm{M}$ & 2,2 & 56,6 & 52,9 & 13,5 \\
Kolkhozny & $\mathrm{L}$ & $1^{\text {st }}$ Sept. & $\mathrm{MS}$ & 2,4 & 47,5 & 59,9 & 15,0 \\
Cosmic & $\mathrm{M}$ & $1^{\text {st }}$ Sept. & $\mathrm{S}$ & 1,9 & 60,2 & 59,2 & 12,0 \\
Krasivy & $\mathrm{ML}$ & $4^{\text {th }}$ Aug. & $\mathrm{M}$ & 2,4 & 47,1 & 60,7 & 13,8 \\
Pervenets & $\mathrm{E}$ & $1^{\text {st }}$ Sept. & $\mathrm{S}$ & 2,0 & 46,7 & 59,6 & 12,6 \\
Rannyi & $\mathrm{M}$ & $4^{\text {th }} \mathrm{Jul}$. & $\mathrm{M}$ & 2,0 & 37,7 & 58,5 & 11,5 \\
Sablevidnyi & $\mathrm{L}$ & $2^{\text {nd }}$ Sept. & $\mathrm{S}$ & 2,1 & 53,9 & 60,0 & 12,0 \\
Tien-Shansky & $\mathrm{E}$ & $2^{\text {nd }}$ Sept. & $\mathrm{S}$ & 2,9 & 49,2 & 56,1 & 18 \\
Ugamsky & $\mathrm{M}$ & $2^{\text {nd }}$ Aug. & $\mathrm{M}$ & 2,7 & 42,8 & 63 & 16 \\
Kansaisky & $\mathrm{M}$ & $1^{\text {st }}$ Sept. & $\mathrm{S}$ & 2,1 & 48 & 55 & 10 \\
P. Uzbek & $\mathrm{E}$ & $4^{\text {th }}$ Aug. & $\mathrm{M}$ & 1,9 & 57,7 & 58,8 & 8 \\
\hline
\end{tabular}

Blooming: $\mathrm{E}=$ early; $\mathrm{M}=$ medium; $\mathrm{ML}=$ medium-late; $\mathrm{L}=$ late.

Shell: $\mathrm{S}=$ =s oft; $\mathrm{M}=$ =medium; $\mathrm{MS}=$ medium-standard; $\mathrm{S}=$ standard; $\mathrm{MH}=$ medium-hard; $\mathrm{H}=$ hard.

Table 2. Some carpological traits on almond accessions recovered in the Bostanlyk area (Uzbekistan) and part of the Ancient Almonds of the International Slow Food Presidium.

\begin{tabular}{lcccccc}
\hline Accession & Nut weight & Nut height & Nut width & Seed weight & Kernel rate & $\begin{array}{c}\text { Double } \\
\text { kernel }\end{array}$ \\
\cline { 2 - 7 } & $\mathrm{g}$ & $\mathrm{cm}$ & $\mathrm{cm}$ & $\mathrm{g}$ & $\%$ & $\%$ \\
\cline { 2 - 6 } & $1,77 \pm 0,03$ & $3,38 \pm 0,04$ & $1,46 \pm 0,08$ & $0,59 \pm 0,02$ & 33,30 & 26,66 \\
Ovarixym & $2,88 \pm 0,07$ & $3,62 \pm 0,07$ & $1,83 \pm 0,04$ & $1,17 \pm 0,04$ & 40,62 & 3,33 \\
Msonngl Sogan & $2,51 \pm 0,04$ & $3,22 \pm 0,07$ & $2,20 \pm 0,07$ & $1,09 \pm 0,02$ & 43,43 & 0,00 \\
Parida Konxopuri & $3,27 \pm 0,08$ & $2,62 \pm 0,04$ & $2,00 \pm 0,06$ & $0,58 \pm 0,03$ & 17,73 & 6,66 \\
Mengall Rogukumi & $2,27 \pm 0,04$ & $3,21 \pm 0,06$ & $1,68 \pm 0,04$ & $0,96 \pm 0,02$ & 42,19 & 3,33 \\
Beaofmr & $2,33 \pm 0,08$ & $3,15 \pm 0,08$ & $1,61 \pm 0,04$ & $1,21 \pm 0,04$ & 51,93 & 63,33 \\
Parifa Buhuyts & $2,15 \pm 0,04$ & $3,19 \pm 0,04$ & $1,78 \pm 0,06$ & $1,03 \pm 0,02$ & 47,68 & 10,00 \\
Cyfuxon & $3,00 \pm 0,08$ & $3,29 \pm 0,04$ & $1,87 \pm 0,04$ & $0,86 \pm 0,03$ & 28,83 & 0,00 \\
Parida Prahks & $3,08 \pm 0,08$ & $2,85 \pm 0,07$ & $1,94 \pm 0,07$ & $0,52 \pm 0,03$ & 16,88 & 0,00 \\
Korati Caope & $2,08 \pm 0,04$ & $2,69 \pm 0,04$ & $1,65 \pm 0,04$ & $0,81 \pm 0,03$ & 38,94 & 0,00 \\
Mengain & $1,61 \pm 0,04$ & $2,69 \pm 0,06$ & $1,72 \pm 0,07$ & $0,62 \pm 0,04$ & 38,50 & 13,33 \\
Tucta & $2,24 \pm 0,08$ & $2,93 \pm 0,04$ & $1,73 \pm 0,04$ & $0,78 \pm 0,02$ & 34,82 & 26,66 \\
Wupunre & $1,99 \pm 0,07$ & $2,66 \pm 0,08$ & $1,63 \pm 0,04$ & $0,60 \pm 0,03$ & 30,15 & 13,33 \\
Lannacs & $1,61 \pm 0,04$ & $2,82 \pm 0,06$ & $1,66 \pm 0,07$ & $0,59 \pm 0,02$ & 36,64 & 0,00 \\
Tokaemenm & $1,53 \pm 0,08$ & $2,51 \pm 0,04$ & $1,65 \pm 0,06$ & $0,44 \pm 0,03$ & 28,75 & 6,66 \\
Ktomod & & & & & &
\end{tabular}

